\title{
Fostering New Roles for Librarians: Skills Set for Repository Managers - Results of a Survey in Italy
}

\author{
Maria Cassella \\ University of Turin, Via Po, 17, Turin, Italy, \\ maria.cassella@unito.it \\ Maddalena Morando \\ Polytechnic of Turin, Corso Duca degli Abruzzi, 24, Turin, Italy, \\ maddalena.morando@polito.it
}

\begin{abstract}
The open access movement in scholarly communication has grown considerably over the last ten years and it has driven an increase in the number of institutional repositories (IRs). New professional roles and skills had to be developed to secure effective IR management.

Collection developmente expertise and metadata curation are regarded as strategic roles for repositories and therefore it is only logical for the library and information community to take on the responsibility for managing these digital archives. However, it has become clear that traditional librarian skills do not suffice anymore to run successful repositories. A richer set of skills is needed, including management and communication skills, technical skills, and expertise with regard to access rights and preservation of digital content.

Referring to the work carried out by the SHERPA Project in the UK with regard to the skills set for repository staff, the authors performed a survey among repository managers in Italy to assess the educational and professional background of the repository managers and the skills set required to implement successful institutional repositories.
\end{abstract}


The survey findings show that the professional profile of the repository manager is a multiform and complex one. It requires cross-functional and highly specialised competencies. Italian repository managers are of the opinion that the skills required to promote the repository within the institution and those required to deal with copyright issues as the most essential skills repository managers should acquire and be trained for. Collection development and metadata expertise, familiarity with project management and expertise in repository workflow design are also highly rated. Technical skills are needed to deal with interoperability standards and protocols.

In Italy academic curricula do not meet the repository managers' educational needs. Academic programmes should be developed to include communication, project management and team work skills and pay more attention to copyright issues. Until that time repository managers will have to spend a considerable part of their working lives on professional training and self-directed learning.

Key Words: institutional repositories; repository management; repository manager; repository administrator; professional roles in librarianship

\section{Introduction}

Since the launch of the Budapest Open Access Initiative in 2002, the Open Access (OA) movement, advocating free and immediate access to scholarly peer-reviewed literature, is gaining progressive acceptance among researchers' communities. ${ }^{1}$ As is well known, the OA movement has defined two strategies to make scholarly outputs freely available on the Internet:

- the Gold Road, i.e., direct publication in Open Access journals;

- the Green Road, i.e., self-archiving or archiving of the scholarly publications in Open Access digital repositories, both subject-based and institutional repositories (IRs).

Two Open Access advocates have been discussing whether or not these strategies are complementary: Stevan Harnad arguing that the Green Road is the main strategy to achieve the goals of the OA movement, and Jean-Claude Guédon claiming the two are complementary strategies. As a matter of fact both the Green and the Gold Road are contributing to the advancement of OA and in some cases they are even converging, as differences between reposi- 
tories and e-journals are beginning to blur ${ }^{2}$ and new journal models point in the direction of an overlap between the two strategies. ${ }^{3}$

Changes in scholarly communication prompted by the OA movement also led to important organizational changes in universities, research institutions and academic libraries. Academic libraries have supported OA principles and initiated OA projects from the beginning as it is their mission to give broad access to scholarly literature. As a consequence, new roles emerged for academic librarians.

In this paper we will discuss the roles and the skills involved in the implementation and management of institutional repositories.

\section{Institutional Repositories in Academic Libraries}

In the last ten years the number of institutional repositories has increased constantly. According to van der Graaf, for example, there is an annual increase of approximately 25 to 35 institutional repositories in Europe, the great majority of repositories (41.6\%) having become operational in 2004 or earlier (Graaf, van der, 2009, p. 33). OpenDOAR, the international directory of Open Access Repositories, in May 2011 lists more than 1800 repositories worldwide.

Very early on, academic libraries were the organizational units that took up managing these repositories, and several studies show that most repository managers are in fact librarians. In 2006 a survey conducted by the Association of Research Libraries (ARL) found that the majority of repositories of ARL members were run by library units (Bailey, 2006). In 2007 respondents to the MIRACLE census of institutional repositories in the United States included almost $75 \%$ library directors, followed by $10.2 \%$ library staff and $7.9 \%$ assistant/associate librarians (Markey et al., 2007, section 2.1). In 2009 Kennan and Kingsley studied the Australian institutional repository landscape and found that, with a few exceptions, institutional repositories were the responsibility of the institution's library. Moreover, $71.1 \%$ of the repository managers had a librarian background (Kennan and Kingsley, 2009). More recently Wickham reported on a survey carried out in 2010 among the United Kingdom Council of Research Repositories members by the Repositories Support Project; the study found that $78.6 \%$ of staff working in UK repositories belonged to the library information community (Wickham, 2010, p. 3). 
For libraries, taking stewardship of institutional repositories is an opportunity to get more deeply involved in the shift in scholarly communication and support that shift; for librarians, it is an opportunity to reengineer their knowledge about access control, metadata, preservation and format migration, and gain new skills and roles.

On the other hand it should be recognized that the fact that libraries have taken control over institutional repositories also represents an organizational weakness:

- first of all, librarians may not be able to gather the strong political commitment institutional repositories need to be successful;

- secondly, librarians sometimes have a tendency to run repositories in an exclusive way (Ottaviani and Hank, 2009, p. 18).

Clifford Lynch observed early in 2003: 'an effective institutional repository of necessity represents a collaboration among librarians, information technologists, archives and records managers, faculty and university administrators and policy makers' (Lynch, 2003). However, in Italy we have observed in the last years a trend to put the responsibility for repositories exclusively with libraries.

Last but not at least, faculty may dislike the fact that an IR is managed by a central institutional unit, whatever it is. The central repository organizational model is often perceived to be at odds with researchers' needs. ${ }^{4}$ As Oya Rieger acutely points out: 'some faculty members are put off by the concept of institutional and may hesitate to share their documents on an open access system run by an institution' (Rieger, 2008).

\section{Role and Skills Set for Repository Management: Literature Review and National Initiatives}

A plethora of studies have explored the professional role of a digital librarian and the skills required to manage digital libraries. Many articles on IRs describe the involvement of librarians, but to date only a few studies focus specifically on the knowledge requirements for managing successful repositories. ${ }^{5}$ 
Allard et al. performed a content analysis of the literature on IRs early in 2005 (Allard et al., 2005). By examining a sample of 30 articles published up to October 30, 2004, the authors identified six emerging roles and responsibilities for librarians involved in the planning, implementation, and management of repositories: understanding IR software, project management and planning, collection definition and development, metadata standards expertise, quality control of content and metadata consistency, and author training.

In 2007 Walters identified the professional librarian positions necessary to shape and define successful IR services: cataloguers, systems librarians, reference librarians and special collections librarians/archivists. He generically concludes that 'support for IRs involves many skills, ranging from the ability to create metadata and integrate information systems to the ability to promote the IR as an indispensable information management tool' (Walters, 2007, p. 223). Corral presented a model of blended information professionals based on three traditional specialist professional groups and includes repository librarians in the e-content and digital library specialists group (Corral, 2010).

Wickham reported the results of a survey carried out in August 2010 in the UK on the professional background of repository managers and discussed the key competencies for repository staff. She identified three roles associated with repositories development:

- 'Repository management - strategic and financial management, advocacy and communication, staff and project management, expert advice to the institution.

- Technical - knowledge and experience of software platforms and the main repository software and its lifecycle of deployment, testing, upgrading and development.

- Administrative - adding records, checking metadata and copyright ${ }^{\prime}$ (Wickham, 2010, p. 5).

As a matter of fact the United Kingdom is leading the way in identifying and defining roles for repository management. In 2007 the United Kingdom Council of Research Repositories (UKCoRR) was funded as an independent body for repositories staff in the UK. UKCoRR goals are to promote repository management as a recognized and respected profession, to provide a forum for discussion on IRs, and to represent the views and concerns of those 
who work with repositories in organizational, policy and strategic development. Membership is limited to UK repository staff.

In 2007 UKCoRR members and SHERPA partners promoted a deep analysis of the skills necessary to run a repository and in August 2007 SHERPA published the first version of the document 'Repository staff and skills set' which was designed to meet the need to describe job positions for repository staff recruitment.

The SHERPA document essentially identifies two roles in repository management:

- The Repository Manager - who manages the repository policies, the advocacy and communication programme, the internal and external liaisons;

- The Repository Administrator - who manages the technical implementation, customisation of the repository software and develops value-added technical services for users (SHERPA, 2007 and SHERPA, 2009).

Two years later, in March 2009, Joint Information Systems Committee (JISC) commissioned Brunton Consultancy Ltd. to prepare a toolkit for assisting university managers in recruiting skilled staff for digital repositories. The document, entitled 'Recruitment Toolkit for JISC digital repository Projects', deals with the whole recruitment process from planning and advertising to interviewing and the job offer. It provides different possible job positions associated with digital repositories as a whole, i.e.,: software developer, web developer, project researcher, digital repository project officer, digital repository project analyst, digital repository metadata librarian, digital repositories manager.

With regard to the skills needed to manage a digital repository the JISC toolkit makes an essential distinction between technical skills, non-technical skills and behavioural competencies (JISC, 2009).

\section{Institutional Repository Landscape in Italy}

To date no comprehensive survey of the Italian repositories' landscape has been conducted in Italy. A few reports on Open Access in Italy (Cassella, 
2009; Miconi, 2010; Gargiulo and Cassella, 2010) have explored Italian OA advancements on the whole and the growth of the national repository landscape. Repositories have come into being mostly after 2004. In May 2011, 60 Italian repositories are listed in the OpenDOAR, the majority of them being implemented in the last four years. ${ }^{6} 42$ out of 60 are university institutional archives. Out of these, three repositories are implemented by university departments (i.e., the Dipartimento di Fisica e Astronomia, University of Catania, Catania, the Dipartimento di Scienze del Linguaggio, Università Cà Foscari, Venice, and the Dipartimento di Matematica, Polytecnic of Milan, Milan). Some universities (Bologna, Milan, Padua, Pisa, and Trento) have implemented more than one repository.

The remaining repositories are part of different types of research centre: the Istituto Superiore di Sanità (ISS) = the Italian National Health Institute, the Consiglio Nazionale delle Ricerche $(\mathrm{CNR})=$ National Research Centre ${ }^{7}$, the Istituto Nazionale di Geofisica e Vulcanologia $(I N G V)=$ the National Institute of Geophysics and Vulcanology, the Istituto Italiano di Medicina Sociale (IIMS) = Italian Social Health Institute, the Scuola Superiore della Pubblica Amministrazione Locale $($ SSPAL) $=$ The Higher School of Public Local Administration, the Abdus Salam International Centre for Theoretical Physics, and a handful of other research centres. The European University Institute, the American University of Rome and the FAO also maintain archives located in Italy, though strictly speaking they are not Italian institutions.

According to Gargiulo and Cassella the total number of items archived in Italian repositories amounted to 200,872 in December 2009 (Gargiulo and Cassella, 2010, p. 74). A typical research repository in Italy contained 3,652 items as assessed in December 2009. This average is much lower than the European average of 8,545 items assessed by van der Graaf in September 2009 (van der Graaf, 2009, p. 45).

The number and the types of items deposited varies greatly between Italian repositories and is not really comparable. The majority of repositories still contain more metadata than accessible full-text papers, although it is their intention to provide wider access to their institutional academic output.

In two cases, i.e., AIR of the University of Milan and the Bicocca Open Archive, Bicocca University, Milan, the choice was made to commit the repositories to the function of Current Research Information Systems (CRIS). 
The great majority of Italian repositories is run by librarians working in university or research centre libraries. This is because the Italian OA movement has mainly pursued a 'bottom-up approach' in that it entrusted advocacy issues, $\mathrm{OA}$ initiatives and repository planning and management to librarians and to a few 'early adopters'. Also, IRs were considered to be a natural extension of the academic digital library from the start.

\section{The Survey: Goals and Method}

Being repository managers ourselves, we realized that the competencies of the repository staff were a key success factor in running our repositories. In 2011, we therefore decided to conduct an online survey among Italian repository managers to question them about their education, training and skills.

In accordance with the SHERPA document (SHERPA, 2007 and SHERPA, 2009) we identified two main roles associated with the deployment of IRs:

- the repository manager, i.e., the role that strategically manages the repository policies. It is the leading position in repository management;

- the repository administrator, who is responsible for the technical implementation of the repository software and for developing valueadded technical services for users.

It was not our goal to analyze the librarian's role as OA liaison officer, who offers local support to the activity of self-archiving in the repository and promotes OA principles locally. The main goal of our study was to analyze the repository manager's skills in order to:

1) help repository managers identify and develop the skills necessary to run a successful repository;

2) build job descriptions for repository posts;

3) design an educational and professional framework to train competent repository managers and administrators.

The survey was carried out through an online questionnaire, for which we customized the open source survey tool 'LimeSurvey' on a server of the Polytechnic of Turin. The survey was made available in February 2011 and 
promoted on three Italian discussion lists: two out of three lists are specifically dedicated to Open Access topics and themes: oa-italia@openarchives. it and oa-crui@openarchives.it. The first list covers all OA issues and is open to anyone interested. The second is the discussion list of the Working Group on Open Access of the Conference of Italian University Rectors (CRUI). The third list is AIB-CUR@LIST.CINECA.IT, the discussion list of Italian-speaking librarians.

By publicising the survey on three discussion lists we can assume that we succeeded in reaching out to the staff of all 60 repositories which were active in Italy at the time of the survey. As the total number of full survey responses was 33 , we obtained a response rate of $55 \%$.

The online questionnaire was divided in two sections (Table 1):

- Section A, composed of 17 questions in which we explored the educational background and the professional training of the repository managers.

- Section B, composed of 23 questions in which we focused on the skills that repository managers regard as most essential to run a repository.

Table 1. Types of survey questions.

\begin{tabular}{|l|l|}
\hline Open questions & 4 \\
\hline Closed questions & 36 \\
\hline Total no. of questions Section A & 17 \\
\hline Total no. of questions Section B & 23 \\
\hline Total no. of questions & 40 \\
\hline
\end{tabular}

The 23 questions of Section B were organized in 5 subsections: Communication, Management,

Technical Issues, Intellectual Property Rights, Collection Development and Metadata. Each of the five sections related to specific types of skills involved in managing a repository. We asked the respondents to rate the answers on a 5 -point Likert scale from $1=$ not important to $5=$ very important. 


\section{Survey Results}

\section{Section A}

$64 \%$ of the respondents (21 responses) to the survey identified themselves as repository managers and only $9 \%$ indicated they were repository administrators ( 3 responses). 27\% (9 responses) were both repository manager and repository administrator.

$45 \%$ of the respondents had been working as repository manager for less than 3 years. Three years is a very short time indeed to consolidate a new professional role and to develop a recognized and respected profession. The context is also to be taken into account: in our experience small and mediumsized universities are more suitable environments for Open Access initiatives, because the relationship with internal decision makers and stakeholders is closer and more effective. Another factor contributes to the lack of professional recognition for repository management in Italy: the great majority of Italian repository managers ( $94 \%$ of the respondents $=31$ responses) works part-time, with an average of 8.3 hours per week spent on the repository. However, 39\% indicated that they were supported by 2 part-time staff and $36 \%$ by 3 part-time staff.

The limited number of FTEs working in an institutional repository is indeed a critical issue in the Italian Open Access framework, especially since the 'Guidelines for institutional repositories' of the CRUI Working Group on Open Access recommend at least 1,5 FTE for the repository start-up phase and 2,5 FTE for ongoing operations (CRUI, 2009, p. 12). This is also a sign of rather limited political and institutional commitment to Open Access issues in Italy, although in 200774 out of 80 Italian Rectors signed the 'Messina Declaration' supporting the 'Berlin Declaration on Open Access to Knowledge in the Sciences and Humanities'.

$67 \%$ of Italian repository managers/administrators have an academic degree, $30 \%$ have a master's. In 2006 Italian universities offered 45 first-level threeyear degrees (Bachelor's degree) and 23 two-year master degrees in Library and Information Sciences ${ }^{8}$. In Italy to date no academic curriculum covers the basic requirements of repository management; a specialized education on digital libraries, in general, can be acquired only in a few masters, i.e., the International Master in Digital Libraries Learning of the University of Parma. 
As the Italian educational framework is unable to meet the very specific requirements of repository managers, professional training becomes extremely important to develop the skills needed to manage a repository. In our survey we asked the repository managers if they had attended any professional courses on IRs and how many professional courses on IRs or $\mathrm{OA}$ issues in general they had attended before setting up their repositories. $55 \%$ of respondents had received specific professional training before setting up the repository and $45 \%$ had completed from one to three courses, the main topics of the courses being Open Access and digital libraries in general, and, more specifically, institutional repositories, copyright issues, OAI architecture, research assessment, metadata, and digital preservation. In Italy professional training on IRs is mainly supplied by the two supercomputing consortia, CILEA and CASPUR.

In an emerging professional sector such as repository management, self-directed learning and self-training are also an essential part of the daily working practice. We therefore asked our colleagues how many hours per week they dedicate to keeping up to date by means of mailing lists, tutorials, personal readings (articles and reports), and so on. 55\% of the respondents replied that they spend from 1 to 5 hours a week on self-directed learning. Open source software user communities also provide special support to repository managers and administrators. EPrints staff, for example, is supported by the 'EPrints wiki' and the 'Tech list'. 'EPrints Services' also provide an ongoing customised training for EPrints repository managers. If repository management is outsourced, the service provider also offers support and consultancy. In Italy both CILEA and CASPUR work as service providers for digital libraries.

\section{Section B}

Appendix A gives a detailed overview of the results in Section B. Below are some of the main findings:

\section{Communication}

In academic libraries communication skills are extremely relevant. They are 'an essential part of formal and informal liaisons with academics' (Horwood et al., 2004, p. 172). Survey findings show that the ability to communicate and promote the IR to faculty, research communities, and 
administrative units (IT area, research area, legal units) and the ability to manage liaisons and to be able to communicate with internal leadership (rectors, provosts, deans and so on) are seen as by far the most relevant communication skills for a repository manager (55\% rated the skills to advocate an IR to faculty, research communities and administrative units at 5; 52\% rated the ability to promote it to the internal leadership at 5).

The ability to plan and support an institutional advocacy programme is also rated as very important by the respondents ( $36 \%$ rated this ability at 5, $27 \%$ at 4). Promoting the IR to external stakeholders is regarded less important (the ability was rated at 3 by $27 \%$, at 4 by $15 \%$ and at 5 by $21 \%$ ).

These results clearly demonstrate that:

a) the main stakeholders of an institutional repository are the internal ones. External stakeholders (policy makers, professional communities, SMEs, funding agencies) should be taken into account as well as they can contribute to the repository's long-term sustainability, ${ }^{9}$ but an IR is foremost 'a set of services' for the internal research communities;

b) it is the main challenge for repository managers in Italy to raise internal stakeholders' awareness with regard to open access issues.

Therefore we suggest that repository managers should focus their attention on internal advocacy initiatives (i.e., training courses) and support services for internal communities (tutorials, help-desk, personal counselling) rather than investing in events primarily addressed at external stakeholders (workshops, conferences, and meetings).

\section{Management}

Familiarity with project management and planning repository activity workflow are rated at 5 by $52 \%$ and $42 \%$ of the respondents respectively. Highly rated is also the ability to manage human resources and team work (42\% rating at 5); slightly less important are regarded both the skills to carry out qualitative surveys (39\% rating at 4, 21\% rating at 5 ) and to collect, harmonize, and validate data and statistics of the repository activities (36\% rating at 4, 18\% rating at 5). These results seem to suggest that repository managers evaluate the above-mentioned abilities important but slightly less pertinent to their professional profile. As a matter of fact qualitative studies are complex and 
time-consuming and should always be carried out by a multi-professional team, including librarians, statisticians, sociologists, anthropologists and so on. Statistics production and evaluation also require the collaboration of statisticians and IT units.

$30 \%$ of respondents rated the ability to plan the repository budget at 3 . This is a distinctive feature of the Italian academic context where the budget is mainly planned and managed by the central administrative units and fund raising is regarded a responsibility of institutional leadership.

Therefore fund raising is not recognized as a specific task of a repository manager (12\% rated the ability to plan fund raising strategies at 5$)$.

\section{Technical issues}

As far as the technical skills are concerned $33 \%$ of respondents rated the competencies with regard to interoperability standards and protocols (OAI-PMH, OAI-ORE, but also standards emerging from the research assessment context, i.e., CERIF) at $5,{ }^{10}$ and $45 \%, 33 \%$ and $30 \%$ respectively rated the skills to customise the IR's web layout, to set up value-added services, and to implement digital preservation procedures at 4 . The importance assigned by the respondents to the repository interface and design is not surprising. First of all repository managers are fully aware of the fact that the repository's branding is essential for both institutional and faculty commitment. Secondly librarians pay a lot of attention to customizing the repository interface as they traditionally collaborate with webmasters or are webmasters themselves.

Increasingly, librarians are also taking on responsibilities with regard to digital preservation. Since 2006 the library community has been involved in many digital preservation projects: CASPAR, PLANETS, the SHERPA Digital Preservation Project and more recently the KeepIt project (April 2009September 2010) which aims to close the gap between the digital preservation community and people responsible for live repositories by focussing on two key areas: training for digital preservation of repository staff and development and implementation of preservation tools for repositories.

Not surprisingly, skills to deploy and manage repository software are rated at 3 by the majority of repository managers, as these are part of the repository administrator's profile. 


\section{Intellectual Property Rights}

Expertise with regard to intellectual property rights received a high rating. As a matter of fact, in the experience of repository managers, authors' lack of knowledge of copyright issues is becoming a major obstacle to masspopulating the repositories. ${ }^{11} 58 \%$ and $55 \%$ of respondents respectively rated the knowledge of copyright terms in the digital environment and the ability to negotiate Open Access clauses and self-archiving licenses with publishers at 5 .

In Italy researchers have a very low level of awareness of copyright issues. To date, there is no database which collects Italian publishers' OA policies like SHERPA/RoMEO which covers mainly Anglo-American publishers ${ }^{12}$; many Italian publishers do not even have or declare a clear policy with regard to self-archiving in repositories. Therefore, repository managers' customised consultancy on legal issues with respect to self-archiving is a service highly appreciated by authors.

As the use of digital technology has raised the complexity level of copyright issues, librarians have a role to play to broaden the perspective of academic staff on IPR issues (Horwood et al., 2004, p. 173). Therefore, we can expect the emergence of another professional position in the Open Access context, i.e., the role of expert on copyright terms in the OA environment.

\section{Collection development and metadata}

$52 \%$ of the respondents rated at 5 expertise on planning and developing repository collections (what kind of materials can be deposited in the repository: only peer-reviewed articles or every type of institutional research output? Should the repository include only digital-born materials or digitized collections as well? Should it include multimedia materials? Should it include educational objects?).

Knowledge and expertise on metadata sets (Dublin Core, MARC, METS, LOM, PREMIS and so on) was also rated at 5 by the $48 \%$ of respondents.

Both collection development skills (selection of content, planning and negotiation of content priorities, evaluation of the performance of the repository collection, management of preservation issues) and the skills to develop and use 
metadata schema are strategic abilities for successful repository managers. They are traditional aspects of librarianship and are included in the Library and Information Sciences curricula, but they have acquired new meaning in the digital era because of the importance of metadata quality in digital repositories. ${ }^{13}$ As a matter of fact the accuracy, completeness and consistency of metadata improve the interoperability among repositories and help build an effective digital infrastructure for knowledge dissemination (Park, 2009).

\section{Conclusions}

Institutional repositories can still be regarded a relatively recent responsibility of digital libraries, but they are beginning to play a significant role in the transformation of the scholarly communication system. Highly professional staff will be required to support the further development and deployment of the repositories.

Our survey findings show that the repository manager's role is the most important role in repository management in Italy. The position is very complex in that it requires cross-functional and highly specialised competencies.

Italian repository managers' rate their required competencies as follows:

- at the top are communication skills, i.e., the ability to promote the repository and to communicate with academic leadership, faculty, research communities and administrative units; and the ability to manage copyright issues;

- collection development and metadata expertise are also regarded as extremely important, but slightly less than the former, because these are abilities librarians are trained for traditionally;

- familiarity with project management, team work and planning repository activity workflow are also highly rated;

- technical skills are important but mainly in relation to interoperability standards and protocols.

In Italy academic curricula are ill-suited to meet repository managers' educational needs and requirements. They should be expanded to include communication, project management, and team work skills and to pay much more attention to copyright issues. Technical skills related to the OA digital environment should also be developed. 
Professional training is also a critical issue in Italy because there are only two organizations which organize specific courses for repository managers, i.e., the two supercomputing consortia CASPUR and CILEA. As a consequence, self-directed learning and self-training play a major role in repository managers' daily activity.

The high rate of repository managers which declare that they work part-time in the institutional repository $(94 \%)$ is a clear sign that repository management has to date not acquired a recognized professional status in Italy. As a matter of fact only two universities (University of Turin, Polytechnic of Turin) have assigned a definite position to the Open Access project manager; repository managers have no independent recognized role.

This situation is seriously hampering repository development in Italy. Further studies, international exchanges, identification of best practices, and projects in education and professional training for repository management across Europe and worldwide will be crucial to develop an appropriate educational and professional framework for repository management in Italy. ${ }^{14}$

\section{Appendix A: Questionnaire Section B: Results}

\section{Communication}

\begin{tabular}{|l|l|l|l|l|l|}
\hline Abilities & $\mathbf{1}$ & $\mathbf{2}$ & $\mathbf{3}$ & $\mathbf{4}$ & $\mathbf{5}$ \\
\hline $\begin{array}{l}\text { Abilities to communicate and promote the IR to faculty, } \\
\text { research communities and administrative units (IT area, } \\
\text { research area, legal units) }\end{array}$ & $12 \%$ & $6 \%$ & $9 \%$ & $18 \%$ & $55 \%$ \\
\hline $\begin{array}{l}\text { Abilities to manage liaisons and to communicate with } \\
\text { institutional leadership (rectors, provosts, deans) }\end{array}$ & $9 \%$ & $9 \%$ & $15 \%$ & $15 \%$ & $52 \%$ \\
\hline $\begin{array}{l}\text { Abilities to communicate with and promote IR to external } \\
\text { stakeholders (policy makers, enterprises, professional } \\
\text { communities, funding agencies) }\end{array}$ & $18 \%$ & $18 \%$ & $27 \%$ & $15 \%$ & $21 \%$ \\
\hline $\begin{array}{l}\text { Abilities to plan and develop an institutional advocacy } \\
\text { programme in order to support IR activities }\end{array}$ & $\begin{array}{l}12 \\
\text { Ab }\end{array}$ & $12 \%$ & $12 \%$ & $27 \%$ & $36 \%$ \\
\hline $\begin{array}{l}\text { Abilities to organize and handle promotional workshops, } \\
\text { conferences, and meetings }\end{array}$ & $9 \%$ & $15 \%$ & $15 \%$ & $36 \%$ & $24 \%$ \\
\hline $\begin{array}{l}\text { Abilities to organize and handle training sessions, to prepare } \\
\text { tutorials, to activate help-desk services to support IR } \\
\text { management and self-archiving practice }\end{array}$ & $9 \%$ & $6 \%$ & $15 \%$ & $24 \%$ & $45 \%$ \\
\hline
\end{tabular}




\section{Management}

\begin{tabular}{|l|l|l|l|l|l|}
\hline Abilities & $\mathbf{1}$ & $\mathbf{2}$ & $\mathbf{3}$ & $\mathbf{4}$ & $\mathbf{5}$ \\
\hline Project management abilities & $6 \%$ & $3 \%$ & $18 \%$ & $21 \%$ & $52 \%$ \\
\hline Abilities to plan repository activity workflow & $6 \%$ & $3 \%$ & $18 \%$ & $21 \%$ & $42 \%$ \\
\hline $\begin{array}{l}\text { Abilities to coordinate and manage human resources and } \\
\text { team work }\end{array}$ & $6 \%$ & $6 \%$ & $15 \%$ & $30 \%$ & $42 \%$ \\
\hline Abilities to plan a budget & $6 \%$ & $21 \%$ & $30 \%$ & $24 \%$ & $18 \%$ \\
\hline Abilities to plan fund-raising strategies & $15 \%$ & $15 \%$ & $42 \%$ & $15 \%$ & $12 \%$ \\
\hline $\begin{array}{l}\text { Abilities to collect, harmonize and validate data and statistics } \\
\text { about repository activities }\end{array}$ & $6 \%$ & $12 \%$ & $27 \%$ & $36 \%$ & $18 \%$ \\
\hline $\begin{array}{l}\text { Abilities to plan and carry out qualitative surveys and to } \\
\text { evaluate findings }\end{array}$ & $12 \%$ & $6 \%$ & $21 \%$ & $39 \%$ & $21 \%$ \\
\hline
\end{tabular}

\section{Technical aspects}

\begin{tabular}{|l|l|l|l|l|l|}
\hline Abilities & $\mathbf{1}$ & $\mathbf{2}$ & $\mathbf{3}$ & $\mathbf{4}$ & $\mathbf{5}$ \\
\hline Abilities to deploy and manage IR software & $12 \%$ & $6 \%$ & $33 \%$ & $21 \%$ & $27 \%$ \\
\hline $\begin{array}{l}\text { Abilities to implement interoperability standards and } \\
\text { protocols (OAI-PMH, OAI-ORE, CERIF) }\end{array}$ & $9 \%$ & $6 \%$ & $24 \%$ & $27 \%$ & $33 \%$ \\
\hline Abilities to customize IR web pages (layout, design) & $6 \%$ & $6 \%$ & $30 \%$ & $45 \%$ & $12 \%$ \\
\hline $\begin{array}{l}\text { Abilities to develop value-added services and facilities } \\
\text { (download statistics, citation index, rankings, bibliographies } \\
\text { and so on) }\end{array}$ & $9 \%$ & $15 \%$ & $21 \%$ & $30 \%$ & $24 \%$ \\
\hline $\begin{array}{l}\text { Abilities to develop web 2.0 functionalities and tools (alerts, } \\
\text { RSS, wikis, blogs and so on) }\end{array}$ & $9 \%$ & $12 \%$ & $36 \%$ & $33 \%$ & $9 \%$ \\
\hline Abilities to implement digital preservation procedures & $9 \%$ & $12 \%$ & $21 \%$ & $33 \%$ & $24 \%$ \\
\hline
\end{tabular}

\section{Intellectual property rights}

\begin{tabular}{|l|l|l|l|l|l|}
\hline Abilities & $\mathbf{1}$ & $\mathbf{2}$ & $\mathbf{3}$ & $\mathbf{4}$ & $\mathbf{5}$ \\
\hline $\begin{array}{l}\text { Abilities to manage intellectual property rights issues in the } \\
\text { digital environment }\end{array}$ & $6 \%$ & $3 \%$ & $15 \%$ & $18 \%$ & $58 \%$ \\
\hline $\begin{array}{l}\text { Abilities to negotiate Open Access clauses and self-archiving } \\
\text { licenses with publishers }\end{array}$ & $9 \%$ & $12 \%$ & $12 \%$ & $12 \%$ & $55 \%$ \\
\hline
\end{tabular}

\section{Collection development and metadata}

\begin{tabular}{|l|l|l|l|l|l|}
\hline Abilities & $\mathbf{1}$ & $\mathbf{2}$ & $\mathbf{3}$ & $\mathbf{4}$ & $\mathbf{5}$ \\
\hline Abilities to plan and develop the repository collection & $3 \%$ & $3 \%$ & $6 \%$ & $36 \%$ & $52 \%$ \\
\hline $\begin{array}{l}\text { Abilities to select and use metadata sets (Dublin Core, MARC, } \\
\text { METS, LOM, PREMIS and so on) }\end{array}$ & $6 \%$ & $3 \%$ & $30 \%$ & $48 \%$ \\
\hline
\end{tabular}




\section{References}

All URLs were last accessed on the 21th of June 2011.

Allard, Suzie, Thura R. Mack, Melanie Feltner-Reichert (2005): 'The librarian's role in institutional repositories: a content analysis of the literature'. Reference services review, 33(3), pp. 325-336.

Bailey, Charles W., Karen Coombs, Jill Emery, Anne Mitchell, Chris Morris, Spencer Simons, and Robert Wright (2006): SPEC Kit 292 Institutional Repositories, Washington, DC:. Association of Research Libraries, http://works.bepress.com/ ir research $/ 2 /$.

Cassella, Maria (2009): 'L'Open Access in Italia: conquiste recenti, sviluppi futuri'. In Rapporto sulle biblioteche italiane 2007-2008, a cura di Vittorio Ponzani; direzione scientifica di Giovanni Solimine, Roma: AIB, pp. 90-99.

Corral, Sheila (2010): 'Educating the academic librarian as a blended professional: a review and case study'. In Academic Librarian 2 : Singing in the Rain, ALSR 2010, Conference towards Future Possibilities, conference proceedings, Hong Kong, 11-12 March 2010, session 1A, pp. 1-24, http://repository.lib.polyu.edu.hk/jspui/ bitstream/10397/1731/1/Session1A Corrall.pdf.

CRUI (2009): Working Group on Open Access, Guidelines for institutional repositories, Rome, April, http://www.crui.it/HomePage.aspx?ref=1781.

Gargiulo, Paola and Maria Cassella (2010): 'Open Access in Italy'. In OA report in Southern Europe, edited by Lluís Anglada, Ernest Abadal, Madrid: FECYT, http://hdl. handle.net/10760/15140.

Genoni, Paul (2004): 'Content in institutional repositories: a collection management issue'. Library management, 25(6/7), pp. 300-306, http:/ / espace.library.curtin.edu. $\underline{\mathrm{au} / \mathrm{R} \text { ?func }=\text { dbin-jump-full\&local base }=\text { gen01-era02\&object } \mathrm{id}=19655}$.

Graaf, Maurits van der (2009): The European Repository Landscape 2008. Inventory of Digital Repositories for research output, Amsterdam University Press.

Horwood, Lynne, Shirley Sullivan, Eve Young, Jane Garner (2004): ‘OAI compliant institutional repositories and the role of library staff'. Library Management, 25(4/5), pp. 170-176.

JISC (2009): Recruitment Toolkit for JISC digital repository Projects, by Brunton Consultancy Limited, March, http://www.jisc.ac.uk/whatwedo/themes/ informationenvironment/recruitment.aspx.

Kennan, Mary Ann and Danny A. Kingsley (2009): 'The state of the nation: a snapshot of Australian institutional repositories'. First Monday, 14(2), 2 February, http:// firstmonday.org/htbin/cgiwrap/bin/ojs/index.php/fm/article/view/2282/2092. 
Laakso, Mikael, Patrik Welling, Helena Bukvova, Linus Nyman, Bo-Christer Bjoerk (2011): 'The development of Open Access journal publishing from 1993 to 2009'. PloS ONE, 11(6), http://www.plosone.org/article/info:doi/10.1371/journal. pone.0020961.

Lynch, Clifford (2003): 'Institutional repositories: essential infrastructure for scholarship in the digital age'. ARL: a bimontly report, 226, http://www.arl.org/ resources/pubs/br/br226/br226ir.shtml.

Markey, Karen, Soo Young Rieh, Beth St. Jean, Jihyun Kim, and Elizabeth Yakel (2007): Census of Institutional Repositories in the United States: MIRACLE Project Research Findings, February, http://www.clir.org/pubs/reports/reports. html.

Miconi, Maria Teresa (2010): 'L'Open Access in Italia: progressi e prospettive'. In Rapporto sulle biblioteche italiane 2009-2010, a cura di Vittorio Ponzani, direzione scientifica di Giovanni Solimine, Roma: AIB, pp. 149-158.

Ottaviani, Jim, Carolyn Hank (2009): 'Topic 2: libraries should lead the institutional repository initiative and development at their institutions'. Bulletin of the American Society for Information Science and Technology, 35(4), pp. 17-21.

Park, Jung-Ran (2009): 'Metadata quality in digital repositories: a survey of current state of art'. Cataloging \& classification quaterly, 47(3/4), pp. 213-228.

Rieger, Oya E. (2008): 'Opening up institutional repositories: social construction of innovation in scholarly communication', The Journal of electronic publishing, 11(3), http:/ quod.lib.umich.edu/cgi/t/text/text-idx?c=jep;view=text;rgn=main;idno=333 6451.0011.301.

SHERPA (2007): Repository staff and skills set, August, http://www.sherpa.ac.uk/ news/Aug2007-01.

SHERPA (2009): Institutional repositories: staff and skills set, revision August 2009, http://www.sherpa.ac.uk/documents/Staff_and Skills Set 2009.pdf.

Swan, Alma (2008): Study on the availability of UK academic 'grey literature' to UK SMEs: report to the JISC Scholarly Communications Group. JISC, http:/ / eprints.ecs.soton. ac.uk/17667/.

Swan, Alma (2011): 'Institutional repositories - now and next'. In University Libraries and Digital Learning Environments , edited by Penny Dale, Jill Beard and Matt Holland, Ashgate Publishing, http://eprints.ecs.soton.ac.uk/21471/.

Walters, Tyler O. (2007): 'Reinventing the library: how repositories are causing librarians to rethink their professional roles'. Portal: Libraries and the Academy, 7(2), http://muse. jhu.edu/journals/portal libraries and the academy/v007/7.2walters.html.

Wickham, Jackie (2010): 'Repository management: an emerging profession in the information sector'. (conference paper), London, Online information 
meeting, 1-2 December, http:/ / www.online-information.co.uk/online2010/files/ conferencing/50/Wickham,\%20Jacqueline.pdf.

Zhong, Cantao and Meng Wan (2010): 'Exploratory study of quality control mechamism for academic papers in the Internet era: a case study of Sciencepaper Online in China'. In Publishing in the networked world: transforming the nature of communications: proceedings of the $14^{\text {th }}$ International conference on electronic publishing, 16-18 June, Helsinki (Finland), edited by Turid Hedlund and Yasar Tonta, pp. 430-436, https://helda.helsinki.fi/bitstream/handle/10227/599/32zhong wan. pdf? sequence $=41$.

\section{Websites Referred to in the Text}

Berlin Declaration on Open Access to knowledge in the Sciences and Humanities, http://www.zim.mpg.de/openaccess-berlin/berlin declaration.pdf.

CASPUR, http://www.caspur.it/.

CILEA, http://www.cilea.it/.

DigCurV, http://www.digcur-education.org/eng/News/DigCurV-project-launch.

Dulcinea, http:/ / www.accesoabierto.net/dulcinea/default.php?contenido=acerca.

EPrints Services http://www.eprints.org/services/.

EPrints Tech list, http://www.eprints.org/tech.php/.

EPrints Wiki, http://wiki.eprints.org/w/Main Page.

Huddersfield Open Access Publishing (HOAP) Project http://www.jisc.ac.uk/ whatwedo/programmes/inf11/inf11scholcomm/hoap.aspx.

KeepIt, http://preservation.eprints.org/keepit/.

OAK Law Project, http://www.oaklaw.qut.edu.au/about.

OpenDOAR, http://www.opendoar.org/.

UKCoRR, http://www.ukcorr.org/index.php.

\section{Notes}

${ }^{1}$ There are indeed huge differences among scholarly communities in the level of acceptance of the Open Access principles. Some communities, such as the physicists, 
have pioneered the OA movement, while others, such as humanists, are slower in gaining awareness of the OA principles and advantages.

For the growth of OA journal publishing from 1993 to 2009 see Mikael Laakso et al. (Mikael Laakso et al., 2011). The authors estimate an average annual growth rate of $18 \%$ for the number of journals and of $30 \%$ for the number of articles; for the growth of institutional repositories internationally, see Alma Swan (Alma Swan, 2011). Swan calculates an increase of more than one repository for each working day in the last three years worldwide.

${ }^{2}$ Some repositories indeed are beginning to be also used as publishing platforms. See for example the JISC's Huddersfield Open Access Publishing (HOAP) Project. With regard to e-journals PLoSONE, the leading PLoS journal, can be regarded both as a scientific peer-reviewed journal and a repository of articles.

3 'Overlay journals' are an example of how the Green and the Gold Road converge. An overlay journal is a journal which publishes articles selected from the repositories' content. An interesting case of a 'hybrid repository' is Sciencepaper Online (SPO), a Chinese repository which adopts a five-level mechanism to assess the quality of the papers deposited. On SPO see (Cantao Zhong, Meng Wan, 2010).

${ }^{4}$ In our experience departmental repositories are often successful as they are rooted in the daily researchers' community workflow.

${ }^{5}$ A possible reason for this delay in focusing on professional roles and skills of repository staff is the fact that to some extent repositories can be still regarded as an emerging concept and component of digital libraries.

${ }^{6}$ See the graph on the growth of the OpenDOAR database for Italy. At the end of 2007, 27 repositories had been implemented in Italy.

${ }^{7}$ The National Research Centre covers 107 institutes all over Italy. It maintains a centralised archive, PUMA, while the institutes manage their own local repositories.

${ }^{8}$ Source: Italian Libraries Association (AIB)

${ }^{9}$ Policy makers, SMEs, and funding agencies are often funders of OA projects and initiatives. However they also may have a practical interest in accessing to research outputs. Alma Swan (Swan, 2008), for example, provides evidence to the fact that grey literature, mainly usage reports, survey results, statistics, theses, and datasets deposited in a repository, is a 'treasure chest' for SMEs and professional communities.

${ }^{10}$ CERIF is the data model which enables information exchange between CRIS systems. As of 2002 CERIF is developed by EuroCRIS.

${ }^{11}$ Academic authors are rarely aware of the possibility of self-archiving. They are often surprised to learn that it is possible to modify the licensing clauses or to make use of alternative models in publisher contracts. The Science Commons/SPARC 
Addenda and the JISC/SURF License to Publish are two tools which allow authors to add to a license or to retain the right to self-archive a research paper.

${ }^{12}$ Conversely in Spain Dulcinea is a database which collects Spanish publishers' policies regarding self-archiving in repositories. In Australia the OAK Law Project has developed legal protocols for managing copyright issues in the open access environment.

${ }^{13}$ See the project 'Automatic enrichment of OAI metadata by means of computational linguistics methodology and development of services for content-based integration of repositories' launched in 2009 by the Bielefeld University Library with the scope to enhance the subject classification for scientific documents using OAI metadata.

${ }^{14}$ Worth citing is DigCurV, a European project funded by the European Commission's Leonardo da Vinci programme, to establish a curriculum framework for vocational training in digital curation. 